\title{
Dinamismo Econômico do Oeste Metropolitano do Rio de Janeiro: Apontamentos sobre Seropédica e Japeri (2003-2018)
}

Economic Dynamism of the Metropolitan West of Rio de Janeiro: Notes on Seropédica and Japeri (2003-2018)

Dinamismo económico del occidente metropolitano de Río de Janeiro: notas sobre Seropédica y Japeri (2003-2018)

Dynamisme économique de l'ouest métropolitain de Rio de Janeiro: notes sur Seropédica et Japeri (2003-2018)

Robson Dias da Silva, Patrícia Matias de Oliveira e Nathália Figueiredo de Azevedo

\section{OpenEdition}

\section{Journals}

\section{Edição electrónica}

URL: http://journals.openedition.org/espacoeconomia/14061

DOI: 10.4000/espacoeconomia. 14061

ISSN: 2317-7837

\section{Editora}

Núcleo de Pesquisa Espaço \& Economia

\section{Refêrencia eletrónica}

Robson Dias da Silva, Patrícia Matias de Oliveira e Nathália Figueiredo de Azevedo, « Dinamismo Econômico do Oeste Metropolitano do Rio de Janeiro: Apontamentos sobre Seropédica e Japeri (2003-2018) », Espaço e Economia [Online], 19 | 2020, posto online no dia 17 agosto 2020, consultado o 11 setembro 2020. URL : http://journals.openedition.org/espacoeconomia/14061 ; DOI : https:// doi.org/10.4000/espacoeconomia.14061

Este documento foi criado de forma automática no dia 11 setembro 2020.

(C) NUPEE 


\section{Dinamismo Econômico do Oeste Metropolitano do Rio de Janeiro: Apontamentos sobre Seropédica e Japeri (2003-2018)}

Economic Dynamism of the Metropolitan West of Rio de Janeiro: Notes on

Seropédica and Japeri (2003-2018)

Dinamismo económico del occidente metropolitano de Río de Janeiro: notas sobre Seropédica y Japeri (2003-2018)

Dynamisme économique de l'ouest métropolitain de Rio de Janeiro: notes sur Seropédica et Japeri (2003-2018)

Robson Dias da Silva, Patrícia Matias de Oliveira e Nathália Figueiredo de Azevedo

\section{Introdução}

1 As primeiras décadas do século XXI testemunharam um avanço considerável na produção científica qualificada sobre as dinâmicas sociais e econômicas do Estado do Rio de Janeiro. Em contraste com o cenário das décadas anteriores, diversos grupos e instituições de pesquisa passaram a empreender maiores esforços com vistas ao melhor entendimento das fragilidades, dos desafios e das potencialidades que se punham à população e estrutura produtiva fluminense.

2 Isso, por certo, foi em muito estimulado pelo cenário econômico e político vivenciado a partir de 2003. Ainda será necessário mais tempo e distanciamento dos fatos para sua compreensão mais ampla, mas já é possível afirmar que esse período foi qualitativamente diferenciado para a economia fluminense que, à esteira do contexto nacional, sentiu os efeitos das políticas de perfil mais desenvolvimentista e também da 
conjuntura internacional favorável ao grande carro-chefe de sua economia: o petróleo (SILVA, 2012, SILVA, 2017).

3 Entretanto, ainda resta um grande déficit de estudos sobre algumas regiões do estado, em especial sobre parte do recorte metropolitano, como é o caso da porção oeste ${ }^{1}$. 0 Oeste Metropolitano tem se destacado por ser grande exemplo das potencialidades perdidas do capitalismo brasileiro, pela carência de maior desenvolvimento social e por ser um região ainda pouco estudada dentro do campo da economia (SILVA; OLIVEIRA, 2017).

4 A compreensão da dinâmica econômica das regiões metropolitanas brasileiras não pode prescindir do estudo de suas periferias. Cabe pontuar que historicamente esses espaços se integraram à metrópole como lócus da mão de obra, em geral, barata e de baixa qualificação, tendo sido tratados como núcleos dormitórios. Fazem parte de uma estrutura metropolitana com o "[...] núcleo hipertrofiado, concentrador da maioria da renda e dos recursos urbanísticos" (ABREU, 2013, p. 17). Essa dinâmica produziu estratos urbanos periféricos cada vez mais carentes de serviços e de infraestrutura, definindo um modelo que representou o clássico padrão centro-periferia, no qual assume-se uma estrutura dicotômica: "[...] um núcleo bem servido de infraestrutura, onde a ação pública se fazia presente com grande intensidade e onde residiam as classes mais favorecidas, e uma periferia carente dessa mesma infraestrutura, que servia de local de moradia às populações mais pobres, $\mathrm{e}$ onde $\mathrm{a}$ ação do Estado era praticamente nula" (ABREU, 2013, p. 82).

5 Nesse sentido, a noção de cidade dormitório surge para qualificar um determinado território da metrópole pelo conjunto de carências nos serviços públicos básicos, pavimentação das áreas públicas, titularidade da propriedade e pouca proximidade do mercado de trabalho (LAGO, 2007). Por muito tempo se constituíram como um lugar do "abandono", onde faltavam políticas públicas e infraestrutura básica, apresentando inúmeras deficiências nas ofertas de serviços e comércio.

6 Com base nesse contexto, esse artigo busca apresentar e discutir o dinamismo econômico do Oeste Metropolitano do Rio de Janeiro a partir da análise dos determinantes da expansão do investimento em dois de seus municípios de menores índices de desenvolvimento social: Seropédica e Japeri. O estudo se concentra no recente período grosso modo identificado como social-desenvolvimentismo, que compreende em grande parte os governos do ex-presidentes Lula e Dilma. A análise, sempre que possível, avançou para anos mais recentes, tanto para o enriquecimento do estudo, quanto para ampliar as fontes de informações estatísticas sobre a região e os municípios.

7 O artigo está dividido em três partes principais, além desta introdução e das considerações finais. Na primeira, faz-se um breve resgate da trajetória econômica do Estado do Rio de Janeiro, de maneira a permitir maior compreensão da dinâmica analisada como uma etapa de reais mudanças para a região em estudo. A segunda parte apresenta os principais vetores do dinamismo econômico regional, ressaltando as bases da mudança da trajetória de crescimento do investimento e seus efeitos sob as expectativas sociais. A seguir, na terceira, são aprofundadas as análises e caracterização do perfil logístico-industrial, assinalando seu papel como eixo propulsor do crescimento econômico de Seropédica e Japeri. Nas conclusões gerais é realizada a recuperação dos principais pontos analisados ao longo do trabalho. 


\section{O Rio de Janeiro contemporâneo: panorama das problemáticas}

8 O território referente ao atual Estado do Rio de Janeiro tem se destacado na federação brasileira pelas dificuldades de conversão de sua pujança econômica em maior bemestar social para o grande conjunto de sua população. Não obstante a presença de importantes setores produtivos e dos serviços, a economia fluminense vem de longa data sofrendo altos e baixos (mais estes que aqueles) que parecem minar qualquer processo de mudança estrutural de maior fôlego, em especial nas suas periferias (SILVA, 2012).

9 Durante quase setenta anos, a região sofreu com o baixo crescimento econômico frente à economia nacional. Esse período, que alguns chamaram "esvaziamento", (SILVA, 2004, LIMONAD, 1996) resultou do forte crescimento de setores produtivos, tipicamente urbanos, em outros espaços econômicos nacionais, em especial no Estado de São Paulo (SOBRAL, 2013).

10 Nesse período, da mesma forma, a região fluminense sofreu mudanças institucionais de grande monta, que redefiniram amplamente suas trajetórias político e econômica. Tratamos aqui da mudança da capital federal para o planalto central, em 1960, e da fusão entre os estados da Guanabara e do Rio de Janeiro, uma década e meia depois. Os anos 1980 foram especialmente difíceis para a economia do estado, tanto por conta da perda de status político, quanto pela conjuntura nacional extremamente crítica, naquilo que se convencionou a chamar década perdida. O Rio de Janeiro, cuja estrutura econômica era muito nacionalizada, sofre diretamente os impactos da penúria fiscal e do desarranjo monetário (SILVA, 2004).

11 O fim do século passado, por sua vez, traz mudanças de peso para a região. A partir de 1994, mudanças econômicas e institucionais vão se encontrar com movimentos regionais trazendo desafios e possibilidades. Em relação aos desafios, o desemprego e a urbanização não planejada se evidenciam cada vez mais nas periferias do estado. Como potencialidades, as promessas de investimentos no bojo da maior abertura à economia global e, especialmente, as expectativas advindas do petróleo.

12 Entre meados de 1990 e o fim da primeira década de 2000, o petróleo se tornou o principal motor do investimento e crescimento econômico fluminense, com efeitos sob as dinâmicas produtivas e territoriais. Contudo, de maneira geral, esses efeitos foram muito circunscritos às regiões participantes da cadeia logística-produtora, pouco atingindo outras economias locais.

13 De meados da primeira década do presente século até 2016, outros componentes se aliaram à dinâmica petrolífera, prometendo maior vigor e desenvolvimento territorial. Aqui, ganham destaques os investimentos ditos "mega", tanto aqueles destinados aos atendimentos dos diversos megaeventos, quanto megaprojetos logísticos e industriais programados e instalados em algumas partes do território estadual, com maior atenção à região metropolitana.

Um ponto destacado por Klink (2013) é o papel da periferia metropolitana fluminense no padrão de reprodução nesse período. De modo geral, o espraiamento da produção em direção à periferia, que primeiramente gerou polarização do crescimento econômico em partes dos municípios de Nova Iguaçu e de Duque de Caxias, alcançou em seguida as bordas metropolitanas, em especial, sua parte oeste reconhecida pela 
carência social. Nesse cenário, Seropédica e Japeri se destacaram pelo seu ineditismo em atração de investimentos de maior monta e importância para a estrutura econômica estadual.

Enquanto os efeitos dos projetos pró-megaeventos ficaram mais circunscritos à capital do estado e sua vizinhança imediata, os megaprojetos de cunho industrial e logístico tiveram nos territórios da periferia metropolitana fluminense seu grande palco. No espaço metropolitano situado ao leste da Baía de Guanabara, a instalação do Complexo Petroquímico do Estado do Rio de Janeiro (COMPERJ) foi, sem dúvidas, o grande carrochefe dos investimentos e esperanças de crescimento econômico com desenvolvimento social e urbano (SILVA; IRAZABAL-ZURITA, 2019). Na porção oeste, por seu turno, houve uma diversidade maior de projetos, não tão vultoso quanto aquele, mas que em conjunto sinalizaram possibilidades de maior expansão econômica e melhorias sociais para os municípios receptores.

O Arco Metropolitano do Rio de Janeiro (BR-493) foi o grande megaprojeto logístico a pretender unir as dinâmicas econômicas que se consolidaram à leste e à oeste da metrópole. Na sua ponta ocidental, o Arco trazia aos municípios menos desenvolvidos da periferia metropolitana fluminense promessas de modernidade, crescimento, empregos e inclusão social. Em Itaguaí, o Arco permite ligação direta com as atividades portuárias e, especialmente, com complexo industrial-militar responsável pela construção de um conjunto de submarinos convencionais e nucleares.

Contudo, nos municípios vizinhos de Seropédica e Japeri, o Arco Metropolitano ensejou dinâmicas econômicas baseadas, não em decisões estatais de investimento, como observado em Itaguaí (NUCLEP) ou Itaboraí (município situado no Leste Metropolitano onde se localiza o COMPERJ), mas em decisões privadas baseadas em setores industriais de pequeno e médio porte e de logística. Seropédica e Japeri passaram então a ser destino de investimentos privados, de capital nacional e estrangeiro, que buscavam vantagens locacionais muito presentes nesses territórios: a grande oferta de terras, ausência de legislação ambiental mais rigorosa e proximidade às principais vias de transportes do estado.

18 Logo, o crescimento do Oeste Metropolitano fluminense está ligado a construção de uma base de exportação, que desenvolve as economias externas, levando a uma melhor capacitação das cidades dessa região na competição entre si ou com países estrangeiros (AZEVEDO, 2018). O território diverso em seu interior exige estratégias de desenvolvimento capazes de gerar vantagens, tanto nas partes mais avançadas como nas menos avançadas - esse tipo de arranjo evidencia o aprofundamento das atuais contradições do espaço metropolitano, suscitando ainda indagações a respeito dos mecanismos que constroem essa integração.

19 Tal lógica, dá caminho ao processo de metropolização periférica, que permite o desenvolvimento de novas regiões econômicas na periferia, de forma combinada e desigual aos determinantes estruturais das centralidades: “...uma mistura de atraso e modernidade, convivendo lado a lado, [...] espaço e período nos quais um setor moderno pode conviver com o mais atrasado, embora este opere como limitante daquele, mas que, em conjunto, influenciam-se mutuamente, modificando-se." (SCHVARSBERG, 2017, p.315).

20 Historicamente, as regiões novas procuram reduzir esses custos, num esforço combinado para promover o seu bem-estar econômico (HARVEY, 2005). Para North (1977, p. 241), uma região jovem deve contar com fontes externas para suprir o seu 
capital de investimento, o que se torna uma verdade no Oeste Metropolitano, visto que os provedores externos de capital tendem a investir principalmente nas atividades de exportação existentes, em lugar de investir em empresas novas, não testadas.

\section{Dinamismo Econômico do Oeste Metropolitano do Rio de Janeiro (2003-2018)}

21 Composta por 22 municípios $^{2}$, a Região Metropolitana do Rio de Janeiro (RMRJ) foi diretamente influenciada pela dinâmica neodesenvolvimentista do período compreendido pelos governos Lula e Dilma (de 2003 a 2015). Tal como o Estado do Rio de Janeiro como um todo, a RMRJ foi beneficiada pela retomada de ações em prol do crescimento econômico, de base social-desenvolvimentista. Dentro do território metropolitano, chamou muito à atenção o inédito dinamismo observado em sua porção oeste, especialmente nos municípios de Japeri e Seropédica (AZEVEDO, 2018; OLIVEIRA, 2017). A borda oeste metropolitana é formada por esses dois municípios, mais Itaguaí, Paracambi, Queimados (OLIVEIRA, 2015)).

Como indicado no mapa da Figura 1, esse recorte espacial ora em análise, representa a periferia oeste mais distante do conjunto metropolitano, fazendo fronteira com a parte oeste da capital estadual, com a Costa Verde, com o Médio Paraíba e os municípios mais populosos da Baixada Fluminense. Os municípios da borda oeste são menos populosos ${ }^{3}$ que seus vizinhos metropolitanos, e apresentam grande extensão territorial, além de baixas taxas de densidade demográfica ${ }^{4}$. Nota-se grande extensão de "terrenos vazios" 5 e ainda preponderância de morfologia rural.

Figura 1: RMRJ: capital, Leste Metropolitano e Baixada Fluminense, subdividida, além da Baixada "Histórica-Iguaçuana", em "Transição Baixada-Leste Metropolitano" e Extremo Oeste Metropolitano.

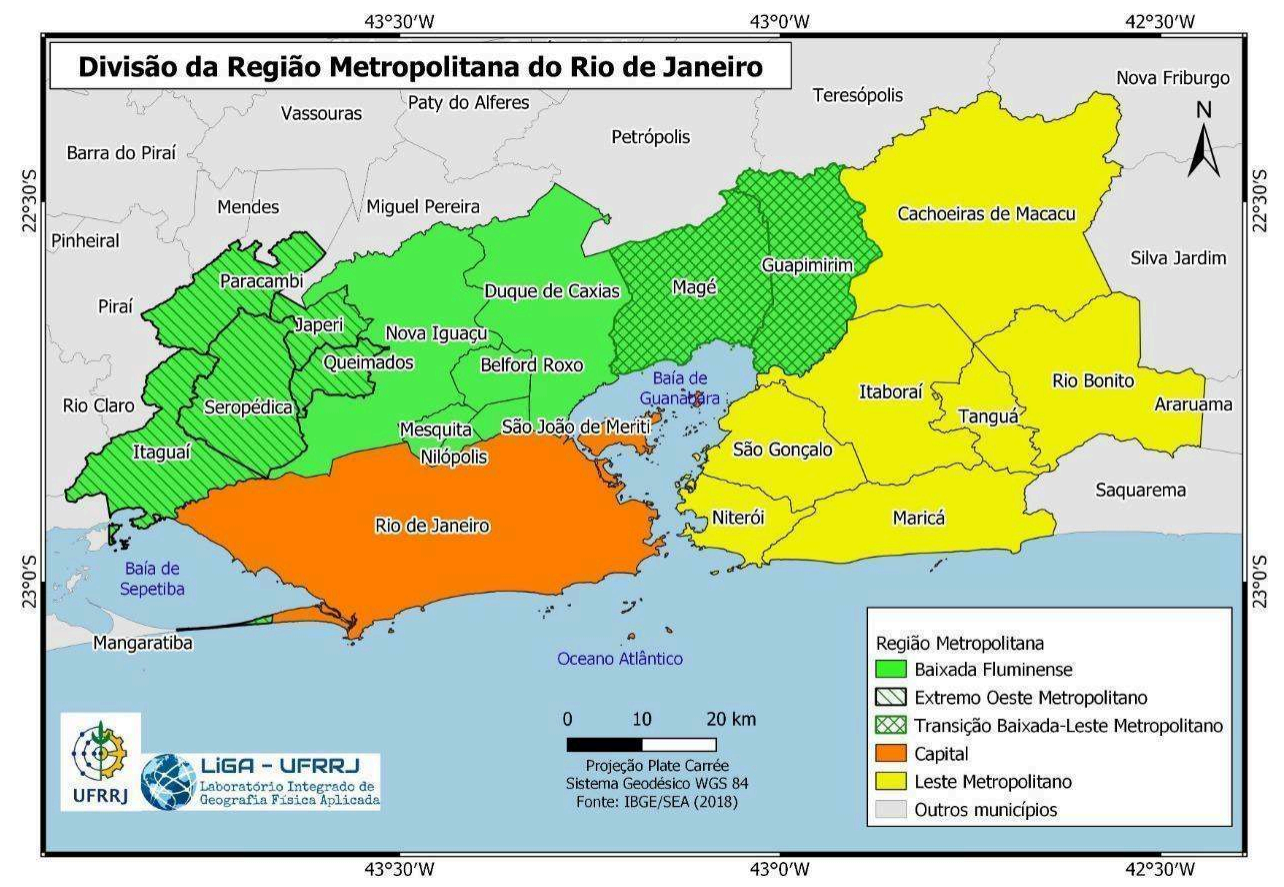

Fonte: FORTES et al, 2020. 
Dados demográficos indicavam que, em 2010, o Extremo Oeste Metropolitano detinha quantitativo populacional da ordem de 467.855 habitantes (IBGE, 2010), número estimado para o ano de 2019 em 522.675 habitantes, segundo projeções do IBGE. Juntos, os municípios que compõem esse recorte espacial somam área territorial de 905,395 $\mathrm{Km}^{2}$, ou seja, $12 \%$ de área metropolitana, respondendo apenas a $2 \%$ da população da RMRJ.

De acordo com os dados estimados para 2019 pelo IBGE (IBGE CIDADES, 2020), Seropédica possui 82.312 habitantes, distribuídos em $283.634 \mathrm{~km}^{2}$. Sua densidade demográfica $\left(275,53 \mathrm{hab} . / \mathrm{km}^{2}\right)$ é bem abaixo da média metropolitana de $1725,82 \mathrm{hab} . /$ $\mathrm{km}^{2}$. Apenas $19,7 \%$ de seu território apresentava urbanização de vias públicas e somente $64,1 \%$ de esgotamento sanitário adequado no último censo (IBGE, 2010).

5 O Município de Japeri, por sua vez, apresenta 104.768 habitantes em seus $81,697 \mathrm{Km}^{2}$. Sua densidade demográfica atinge 1.166,37 hab./ $\mathrm{km}^{2} \mathrm{e}$, em termos de infraestrutura, apenas $26,8 \%$ apresentava urbanização de vias públicas e $68,3 \%$ esgotamento sanitário adequado no último censo (IBGE, 2010).

Em 2017, o Produto Interno Bruto (PIB) do Estado do Rio de Janeiro estava na casa dos $\mathrm{R} \$ 672$ bilhões. Seropédica respondia por $0,6 \%$ desse total, enquanto Japeri a $0,25 \%$. Em termos de PIB per capita, esse era de $\mathrm{R} \$ 49.882,41$, em Seropédica, e de $\mathrm{R} \$ 15.956,10$, em Japeri. Nos dois municípios, os setores de serviços e da administração pública (defesa, educação e saúde pública e seguridade social) se destacam na composição do PIB Municipal (Tab. 1).

Tabela 1: Atividade econômica segundo valor adicionado bruto a preços correntes ( $\mathrm{x}$ 1000) $R \$$, segundo centralidade metropolitana e municípios.

\begin{tabular}{|l|l|l|l|}
\hline ATIVIDADE ECONÔMICA & $\begin{array}{l}\text { Estado do } \\
\text { Rio de Janeiro }\end{array}$ & Seropédica & Japeri \\
\hline AGROPECUÁRIA & $81.546,45$ & $15.822,69$ & $8.614,30$ \\
\hline INDÚSTRIA & $32.417 .782,31$ & $786.535,59$ & $139.363,65$ \\
\hline $\begin{array}{l}\text { SERVIÇOS - EXCLUSIVE ADMINISTRAÇÃO, DEFESA, } \\
\text { EDUCAÇÃO E SAÚDE PÚBLICAS E SEGURIDADE SOCIAL }\end{array}$ & $179.812 .829,42$ & $2.339 .850,83$ & $668.674,47$ \\
\hline $\begin{array}{l}\text { ADMINISTRAÇ̃̃OO, DEFESA, EDUCAÇÃOO E SAÚDE } \\
\text { PÚBLICAS E SEGURIDADE SOCIAL }\end{array}$ & $48.760 .921,61$ & $581.359,81$ & $668.284,10$ \\
\hline
\end{tabular}

8 Fonte: Elaboração própria, com dados do IBGE CIDADES (2020).

Dados de 2018, mostram que o salário médio mensal no município de Seropédica é de 4.1 salários mínimos, enquanto é que de 2.1 salários mínimos em Japeri. Esses números, no entanto, devem ser observados com muita cautela dado que o resultado de Seropédica está diretamente associado aos salários recebidos pelos servidores públicos da Universidade Federal Rural do Rio de Janeiro e Embrapa-Agrobiologia.

A região apresenta muito dos problemas sociais observados em toda a região metropolitana, tais como déficits na habitação, elevados níveis de pobreza e poucos postos de trabalho. Ademais, somente $7,2 \%$ da população estava ocupada no mercado 
formal, enquanto $41.4 \%$ dos seus domicílios viviam com até meio salário mínimo por pessoa. Em Seropédica, por sua vez, o total de ocupados era de $17.5 \%$ e $37.4 \%$ de domicílios viviam com até meio salário mínimo por pessoa.

31 Os números anteriores talvez expliquem o panorama da migração laboral nesses municípios na década de 2010 , no qual, Japeri (56,07\%) e Seropédica (31,34\%) apresentam grande parte de suas populações se deslocando diariamente para outros municípios a fim de trabalhar. Em números absolutos, 107.552 habitantes em situação de vulnerabilidade social retornam diariamente do trabalho aos municípios do Extremo Oeste Metropolitano. Em termos de tempo de deslocamento, em Japeri, 53,5\% da população vulnerável gasta mais de uma hora no deslocamento casa ao trabalho (ATLAS BRASIL, 2013).

Ainda assim são números expressivos que traduzem a necessidade de busca de oportunidades fora de seus limites municipais. Sabemos que a periferia metropolitana como um todo, por muito tempo, serviu majoritariamente como local de moradia barata para a classe trabalhadora da cidade do Rio de Janeiro, apresentando algumas características necessárias como: baixos preços dos terrenos e transporte (RODRIGUES, 2006).

Vimos que a partir dos anos de 2000, Japeri e Seropédica observaram maior ganho de complexidade de suas estrutura econômica. Oliveira $(2015$, p. 5) denomina a região abordada nesse estudo como "Região Logístico-Industrial do Extremo Oeste Metropolitano Fluminense", principalmente porque passa a se apresentar como alternativa às centralidades metropolitanas para o desenvolvimento de atividades fabris ou logísticas, dado que esse tipo de investimento exige maiores espaços e flexibilidade das leis municipais para sua instalação. Configura-se assim, como indicado pelo autor, como área de expansão, influência e polo de propagação da metrópole por diversos incentivos federais e estaduais. Se observarmos o número de estabelecimentos industriais no período de 2003 a 2011, chama atenção o "salto" dos municípios nesse setor: Japeri, por exemplo, tem um crescimento de $130 \%$.

Tabela 2. Número de estabelecimentos industriais Estado e Municípios, segundo ano e crescimento.

\begin{tabular}{|l|l|l|l|}
\hline Município & 2003 & 2011 & Crescimento (\%) \\
\hline Estado & 21787 & 29268 & 34,34 \\
\hline Rio de Janeiro & 9207 & 11349 & 23,24 \\
\hline Itaguaí & 118 & 189 & 60,17 \\
\hline Japeri & 20 & 46 & 130,00 \\
\hline Paracambi & 42 & 70 & 66,67 \\
\hline Queimados & 66 & 122 & 84,85 \\
\hline Seropédica & 73 & 132 & 80,82 \\
\hline
\end{tabular}



municipalidades voltaram-se para ampliação dos distritos industriais e para a criação de zonas de apoio logístico e movimentos de ocupação no entorno da BR-493, impactando diretamente as cidades que intercepta: Japeri, Seropédica e Itaguaí. A implantação do Arco fortaleceu ainda mais a crença na reestruturação territorialprodutiva da região em um cenário de prosperidade, em contraste com seu passado de forte estigma social.

42 A reformulação do Porto de Itaguaí como um dos maiores e mais modernos Portos da América Latina, tem a pretensão de torná-lo o primeiro Hub Port, ou seja, porto concentrador de cargas, do Atlântico Sul. Tal modernização, impactaria de forma direta na geração de empregos, e de forma indireta, na atração de indústrias que necessitavam receber e enviar cargas e se instalaram entre 2003 e 2018 na região (AZEVEDO; SILVA, 2018).

Vale destacar o enorme impacto previsto com o funcionamento do Arco, principalmente em se considerando a integração metropolitana, expectativas compartilhadas pela Câmara Metropolitana de Integração Governamental, (atualmente 
sob nova designação como Instituto Rio Metrópole), que também imaginava essa região como vetor de crescimento populacional. As transformações territoriais e produtivas aqui apresentadas propõem novos desafios às municipalidades, dentre eles, a necessidade de revisão dos Planos Diretores Participativos Municipais instrumento instituído pelo Estatuto das cidades (2001) e obrigatório desde 2006 para atender, principalmente, ao ordenamento territorial e a dinâmica de ocupação e uso do solo. Da mesma forma previa-se a adequação desses instrumentos dois anos após a aprovação do Plano de Desenvolvimento Urbano Integrado (PEDUI) instituído pelo Estatuto das Metrópoles (2015) (SILVA; AZEVEDO, 2018).

Ao pensar os rumos dos municípios metropolitanos, o processo de elaboração, entrega e instituição legislativa do Plano Estratégico de Desenvolvimento Urbano Integrado (PEDUI) da Região Metropolitana do Rio de Janeiro (RMRJ) pelo Poder Legislativo do Estado do Rio de Janeiro, em dezembro de 2019, representa um convite para a reflexão sobre o planejamento metropolitano integrado.

A atual agenda de governo estadual Wilson Witzel (2019-2022) estabelece o fortalecimento de uma Agência Metropolitana (Instituto Rio Metrópole - IRM) frente a efetiva governança metropolitana e incentiva o desenvolvimento do turismo rural como opção econômica frente ao atual processo de desaceleração econômica. O que coloca o turismo como uma opção econômica aos municípios da borda oeste fluminense visto os atrativos naturais e suas características rurais.

Segundo Azevedo (2018), os investimentos em infraestrutura anteriormente citados fizeram com que os municípios do Oeste Metropolitano entrassem na cadeia global de valor do setor logístico-industrial, setor dinâmico da atividade industrial, atraindo inclusive o capital financeiro chinês. O localismo e a endogeneização aparecem nas formulações políticas de atração de investimentos dos municípios, que se baseiam em concessões fiscais (renúncias fiscais) e espaciais, sem compreender o planejamento do ordenamento territorial na escala regional (AZEVEDO, 2018; OLIVEIRA, 2015).

A busca por atração de investimentos, que vai ao encontro da necessidade de criação de postos de trabalho, fez uso do grande estoque de terras que a região tem a ofertar. Isso é reforçado pelo avanço do urbano em áreas tipicamente rurais, no que compete a configuração urbana-rural ou a nova ruralidade desta periferia metropolitana (AZEVEDO, 2018), sendo explorada pelos processos de expulsão, a acumulação por espoliação. Por conseguinte o desenvolvimento desigual destes "vazios urbanos" e espaços destinados à expansão industrial e habitacional, é agravado pelo fato de que estaria disponível para investimentos uma área total de $44 \mathrm{~km}^{2}$ (FIRJAN, 2014).

Além do mais, são áreas com baixos preços médios de locação. No levantamento realizado por Oliveira (2017), podemos visualizar os preços de Queimados e Seropédica em termos comparativos com outros municípios (Tabela 2):

Tabela 2. Preços médios de locação em alguns municípios da RMRJ

\begin{tabular}{|l|l|}
\hline \multicolumn{2}{|l|}{ Preços médios pedidos de locação $\mathrm{m}^{2} /$ mês } \\
\hline Estado do Rio de Janeiro & $\mathrm{R} \$ 23,00 \mathrm{~m}^{2} / \mathrm{mês}$ \\
\hline Avenida Brasil & $\mathrm{R} \$ 35,00 \mathrm{~m}^{2} / \mathrm{mês}$ \\
\hline
\end{tabular}




\begin{tabular}{|l|l|}
\hline Belford Roxo & $\mathrm{R} \$ 25,00 \mathrm{~m}^{2} / \mathrm{mês}$ \\
\hline Nova Iguaçu & $\mathrm{R} \$ 25,00 \mathrm{~m}^{2} / \mathrm{mês}$ \\
\hline Queimados & $\mathrm{R} \$ 18,60 \mathrm{~m}^{2} / \mathrm{mês}$ \\
\hline Seropédica & $\mathrm{R} \$ 18,60 \mathrm{~m}^{2} / \mathrm{mês}$ \\
\hline Campos & $\mathrm{R} \$ 15,00 \mathrm{~m}^{2} / \mathrm{mês}$ \\
\hline
\end{tabular}

Fonte: Oliveira (2017, p. 98)

51 É possível observar que, comparados à média estadual, os municípios apresentam preços um pouco mais baixos. Esses preços dizem respeito à locação de espaços logísticos, demonstrando atratividade por sua acessibilidade e disponibilidade. Áreas localizadas na Avenida Brasil, por exemplo, apresentam quase o dobro do preço. Portanto, as cidades que compõem esta região têm recebido importantes instalações industriais em seus territórios, principalmente de capital estrangeiro (AZEVEDO, 2018). Isso impulsionou o movimento do capital imobiliário-logístico-industrial (LOPES, 2018) na reestruturação de pequenas áreas industriais, em distritos e/ou condomínios industriais pela legislação previstos nos Planos Diretores vigentes de cada municipalidade. Nos anos 2000, o conjunto institucional de Isenções do Imposto sobre Circulação de Mercadorias (ICMS) por parte do governo do Estado também estimulou as empresas a se instalarem nos municípios estudados, principalmente Japeri, após disputa entre os Distritos Industriais e logísticos próximos.

\section{O perfil logístico-industrial como alavanca econômica de Japeri e Seropédica}

Pode-se afirmar que a metropolização periférica em Japeri e Seropédica é um fenômeno originário de uma dinâmica estrutural desigual. A emergência dos condomínios industriais e de áreas de especial interesse industrial deu-se na lógica de reescalonamento do Estado nos anos 2000. Os municípios que compõem a Região Metropolitana do Rio de Janeiro foram, assim, amparados por uma série de benefícios fiscais em favor da indústria e da logística. Dessa forma, esses municípios experimentaram transformações nas múltiplas escalas territoriais de poder e a reestruturação da economia internacional (KLINK, 2013).

53 Para Brandão (2012, p.32), o conjunto de forças desarticulativas nesses multiníveis se expressa na aprofunda crise federativa brasileira e na guerra dos lugares e das escalas que se instala nas estratégias neolocalistas de desenvolvimento local. Elas reforçam características do desenvolvimento desigual e combinado, as disparidades socioespaciais e a fragmentação do espaço nacional (BRANDÃo, 2017).

Com sua emancipação nos anos 1990, Japeri passou a desenvolver algum nível de comércio e especialização local. Surgiram, nos anos 2000, indústrias locais que definiram uma "super-estrutura industrial" suprindo as necessidades pelas matériasprimas locais, principalmente a indústria extrativa. O crescimento da população e da indústria extrativa, além da condição de cidade dormitório, atuaram junto ao maior 
crescimento industrial do município, especialmente mediante a fixação de condomínios industriais.

Baseado nos princípios da teoria da localização de North (1997, p.340), o desenvolvimento de um determinado "artigo de exportação" reflete em uma vantagem comparativa nos custos relativos da produção, sendo regiões novas redutoras de custos. Nessa lógica, a partir de 2006, com o investimento crescente do Estado Brasileiro em infraestrutura, o esforço contínuo por parte governo federal e estadual para reduzir os custos de transferência via a melhoria da logística melhora a posição competitiva dos produtos de exportação no Extremo Oeste.

Assim, o crescimento do Oeste Metropolitano fluminense estaria ligado a uma base de exportação, que desenvolve as economias externas, o que levou uma melhor capacitação das cidades dessa região na competição entre si ou com países estrangeiros. Oliveira (2017) contabilizou os seguintes condomínios industriais e logísticos atraídos para esse território (Tabela 2):

57 Tabela 2. Condomínios Industriais e Logísticos na Borda Oeste Metropolitana.

\begin{tabular}{|c|c|}
\hline \multirow{5}{*}{ Seropédica } & VBL LOG Seropédica \\
\hline & Seropédica Park \\
\hline & Prologis CCP Seropédica \\
\hline & Multimodal Seropédica \\
\hline & Golgi Seropédica \\
\hline Japeri & Condomínios Industriais Marajoara - I, II e III \\
\hline \multirow{6}{*}{ Queimados } & Distrito Industrial \\
\hline & Condomínio industrial e logístico GLP Queimados \\
\hline & Condomínio Logístico Queimados \\
\hline & ENAAX Queimados \\
\hline & Prologis CCP Queimados \\
\hline & $\mathrm{AQ}^{3} \mathrm{Log}$ Queimados- Condomínio Logístico / RJ \\
\hline \multirow{2}{*}{ Paracambi } & Condomínio Industrial I (CI I) \\
\hline & Condomínio Industrial II (CI II) \\
\hline
\end{tabular}

Fonte: Adaptado de Oliveira (2017)

A quantidade de condomínios chama à atenção, principalmente nos municípios de Seropédica e Queimados. São empreendimentos que se aproveitam dos atributos ofertados pela região, principalmente sua posição geográfica e oferta de terras. 
Interessante constatar como a Via Dutra concentra esse tipo de empreendimento, configurando um corredor logístico.

Em Japeri, o ponto de inflexão da questão industrial se deu, em 2005, na criação dos Condomínios Industriais I, II e III no bairro Marajoara junto às áreas da APA (Área de Proteção Ambiental) do Rio Guandu, o que permitiu a instalação de inúmeras empresas de diferentes portes. Destaca-se a unidade fabril da Granado, com a vinda de parte da produção da marca Phebo antes produzida em Belém, PA; a INCOPRE, com préfabricados de concreto; a Embelmar, empresa de envasamento da marca Embelleze; e a Poly Rio Polimeros Ltda., todas às margens da RJ-19 e próxima ao Arco Metropolitano (RJ-493). Merece destaque ainda no município, a presença do Terminal de Japeri da Petrobrás S.A., um dos principais entrepostos para os diferentes modais de transportes, o que garante a confiabilidade do abastecimento de diesel e de gasolina do Terminal de Volta Redonda.

Figura 2 - Delimitação Territorial dos Condomínios Industriais Marajoara: I, II e III - Japeri, RJ.

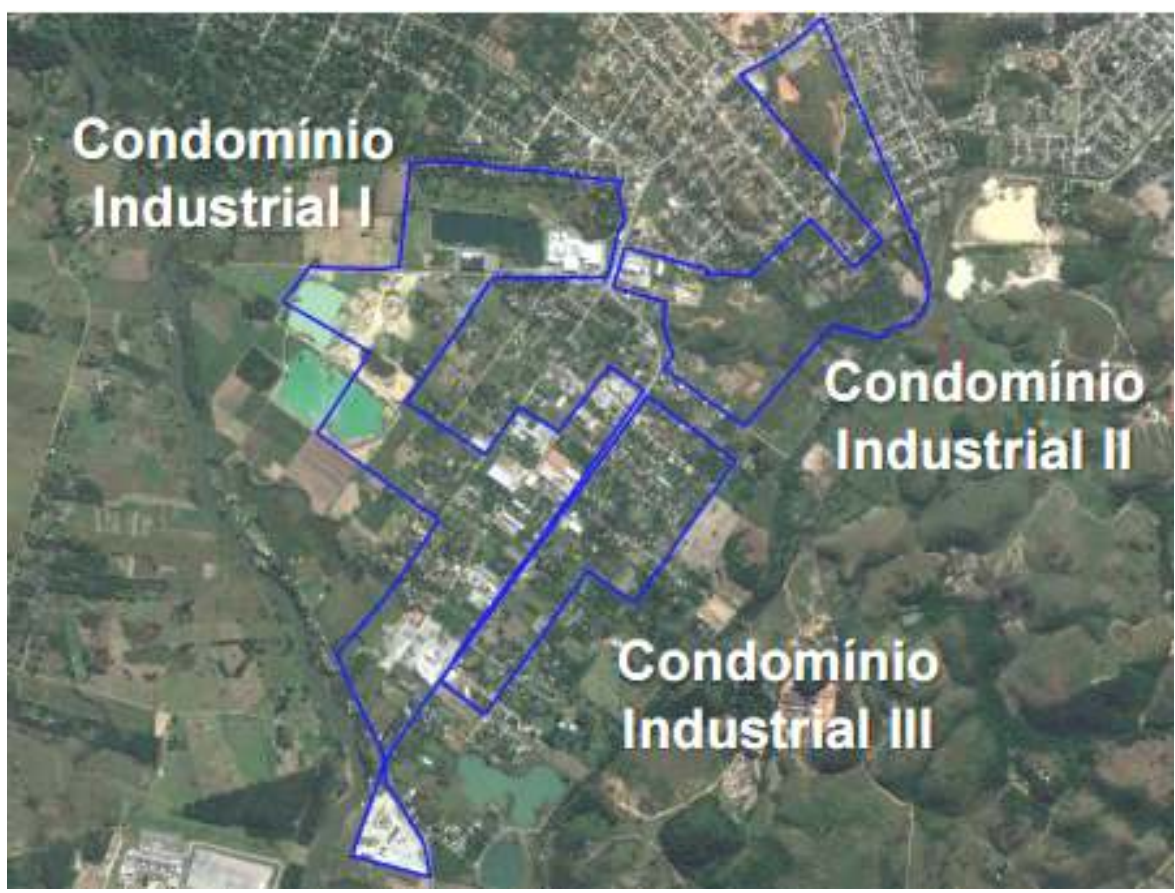

Fonte: Retirado da Apresentação Institucional da Semdic - Japeri (RJ) - dez/2017.

Cabe lembrar que alguns incentivos são concedidos às empresas pelo poder público para atraí-las ao seu território. O governo no Estado do Rio de Janeiro sancionou no ano de 2010, a lei de incentivo fiscal $n^{\circ}$ 5636, de 06 de janeiro de 2010 que dispõe sobre Política de Recuperação Industrial Regionalizada e outras Providências, entre outras medidas permitiu a diminuição da taxa do ICMS (Imposto sobre Circulação de Mercadorias e Serviços) de $19 \%$ para $2 \%$, além de incentivar a entrada de maquinário (máquina, equipamento, peça, parte e acessório), ao adiar o pagamento do crédito tributário para o momento da eventual saída da empresa. Essa lei foi fundamental para atração industrial em grande parte dos municípios do estado, apesar de ser limitada geograficamente a estabelecimentos industriais de algumas cidades: na primeira redação da lei em janeiro de 2010 eram 48 municípios contemplados, a segunda de julho 
do mesmo ano somavam $51^{6}$. Entre os beneficiários estão os distritos industriais das cidades de Queimados, Japeri e Paracambi ${ }^{7}$.

Além desse incentivo na escala estadual, cada município procura adicionar mais vantagens através de leis municipais. Seropédica, por exemplo, não fez parte dos municípios contemplados pela lei $\mathrm{n}^{\circ}$ 5636/2010, porém a cidade traz em seu Plano Diretor de 2006 (cuja última revisão ainda está em elaboração) algumas diretrizes que buscam fortalecer a indústria no município. Adicionalmente, há uma lei que concede benefício fiscal às empresas que nela vierem a se instalar, a Lei Municipal N. 106 de 14 de abril de 2000. Que confere:

63 I - isenção do Imposto Predial e Territorial Urbano - IPTU, incidente sobre o imóvel objeto do investimento pelo período de 20 (vinte) anos; II - isenção do Imposto Sobre Transmissão de Bens Imóveis - ITBI, incidente sobre a aquisição de imóvel no qual será implantado o investimento; III - ficam limitados a alíquota de $1 \%$ (um por cento) do Imposto sobre Serviços de Qualquer Natureza - ISSQN, os serviços de engenharia, construção civil, fornecimento de equipamentos, montagem industrial, operação e manutenção, necessários à implantação e conservação das empresas industriais que vierem a se instalar na Zona Industrial de Seropédica; IV - isenção de Taxas e Emolumentos referentes aos atos administrativos necessários para a regularização do projeto, implantação e funcionamento do Empreendimento.

64 Percebe-se aqui que o município isenta as empresas de IPTU por um período de vinte anos, mais tempo que a boa parte das cidades, entre outros incentivos importantes concedidos, tais como, a isenção de taxas referentes aos atos administrativos necessários para a regularização do projeto, implantação e funcionamento do empreendimento.

Em 2015, o Cadastro Central de Empresas do IBGE (Tabela 3) elencou que em Japeri existem 667 empresas atuantes que geraram 7.614 postos de trabalho e cerca de $\mathrm{R} \$ 166$ milhões em salários e remunerações. Ao passo que em Seropédica havia 2.217 empresas atuantes, que assalariaram mais de 30 mil trabalhadores, gerando massa salarial de cerca de R\$ 917 milhões.

Tabela 3 - Dados selecionados do Cadastro Central de Empresas segundo os municípios (2015).

\begin{tabular}{|l|l|l|}
\hline & Japeri & Seropédica \\
\hline Número de empresas (unidades) & 667 & 2.217 \\
\hline Pessoal assalariado (unidades) & 7.614 & 30.875 \\
\hline Salário mensal (salário mínimo) & 2,1 & 3,4 \\
\hline Massa Salarial (R\$ x 1000) & $166.488,00$ & $917.000,00$ \\
\hline
\end{tabular}

Fonte: Adaptado de AZEVEDO (2018).

68 Em Japeri, parcerias comerciais estão em andamento entre China, Coréia do Sul e Armênia. Há um laço histórico entre Japeri e a China, em função da atuação de imigrantes chineses na construção da ferrovia no século XIX, e um Memorial está sendo 
projetado para celebrar a parceria, entre o Cônsul Geral da China no Brasil Li Yang e o município, e celebrar a memória e a bravura dos que atuaram na construção da malha ferroviária (AZEVEDO, 2018). Tal relação possui reflexos nos números da importação de produtos chineses pelo município, atingindo 1.01 milhão de dólares em 2018 (DATA VIVA, 2020). O maior segmento de importação são produtos de base para as indústrias químicas: ácidos graxos, óleos ácidos e álcoois graxos industriais (26,1\%), seguido pelo importação de maquinário de pulverização $(16,2 \%)$ vindo dos Estados Unidos e que simbolizam $24,7 \%$ de tudo que se importa no município.

69 Japeri destaca-se timidamente no comércio internacional pela exportação, tendo como principal destino a França, com cerca de 661,2 mil dólares de um total de 1,14 milhões no município (DATA VIVA, 2020). 0 maior segmento exportador é o de metais preciosos $(71,8 \%)$, seguido pelo segmento de produtos químicos para maquiagens $(7,6 \%)$. Logo se percebe que a maior parte dos produtos exportados de Japeri está ligada a indústria criativa de jóias e bijuterias.

70 Por sua vez, Seropédica se destaca no comércio internacional pela exportação de produtos cosméticos, tendo como principal destino a Argentina, com cerca de 5,3 milhões de dólares de um total de exportação de um total de 11.7 milhões de dólares (DATA VIVA, 2020). Nesse segmento exportador, incluem-se produtos cosméticos para cabelos $(52,8 \%)$ e produtos para barbear $(24,2 \%)$, seguido pelo segmento de produtos odontológicos $(17,8 \%)$.

\section{Considerações finais}

71 A narrativa escalar e os múltiplos processos permeiam este trabalho na tentativa de responder aos determinantes da expansão de investimentos, que moldaram o dinamismo econômico do Oeste Metropolitano, em especial dos municípios de Japeri e Seropédica, tendo como recorte espacial o período entre 2003 e 2018. A região é marcada por uma expansão demasiadamente tardia de investimentos públicos e privados; e norteada pela reestruturação-territorial-produtiva, metropolização periférica e expansão capitalista.

72 A estratégia de crescimento econômico em Seropédica e Japeri se baseou na atração e investimentos que fizeram uso das características locacionais e da grande oferta de áreas livres, não construídas ou urbanizadas, como atrativo para o grande capital industrial e logístico. Os projetos vinculados a este ramo da economia, muitas das vezes, estavam dissociados da história e da dinâmica urbana e social prévia daqueles territórios, fazendo uso da promessa de emprego e desenvolvimento como chamariz para o conjunto da sociedade.

73 A forte crise vivenciada pelo país e, especialmente, pelo Estado do Rio de Janeiro, desde 2014, paralisou muitos desses empreendimentos, alguns em meio às etapas de instalação, outros ainda em fase de projetos, deixando muitos dos potenciais de crescimento apenas como sonho.

74 Espera-se que em breve a sociedade fluminense possa discutir novamente os caminhos do desenvolvimento e que a população das áreas periféricas, tais como Seropédica e Japeri, possam fazer parte dessa dinâmica em prol de seu bem-estar social, convertendo de fato crescimento em desenvolvimento. 


\section{BIBLIOGRAFIA}

ABREU, M.A. Evolução urbana do Rio de Janeiro. Rio de Janeiro: Editora IPP, 2013.

ATLAS DO DESENVOLVIMENTO HUMANO MUNICIPAL BRASILEIRO - Brasília: PNUD, Ipea, FJP, 2013. Disponível em: http://atlasbrasil.org.br/

AZEVEDO, N.F. As desigualdades territoriais no Extremo Oeste Metropolitano Fluminense: um estudo sobre o Município de Japeri (RJ). 2018. Dissertação (Mestrado em Desenvolvimento Territorial em Políticas Públicas). Seropédica: Universidade Federal Rural do Rio de Janeiro, 2018.

BRANDÃO, C.A. Crise e rodadas de neoliberalização: impactos nos espaços metropolitanos e no mundo do trabalho no Brasil. Cadernos Metrópole, v. 19, p. 45-69, 2017.

BRANDÃO, C.A. Território e Desenvolvimento: as múltiplas escalas entre o local e o global. 2. ed. Campinas: Ed. Unicamp, p. 238, 2012.

CEPERJ. Anuário Estatístico Fluminense 2013. Disponível em: http://arquivos.proderj.ri.gov.br/ sefaz_ceperj_imagens/Arquivos_ceperj/ceep/dados-estatisticos/anuario-online/Anuario2013/ index.html. Acesso: 10/08/2020.

DATAVIVA. Disponível em: http://dataviva.info/pt/about/ Acesso 10/08/2020.

FIRJAN. Avaliação dos Impactos Logísticos e Socioeconômicos da Implantação do Arco Metropolitano do Rio de Janeiro, 2008. Disponível em Acesso em: 02/08/2020.

FIRJAN. Representatividade empresarial para fortalecer a indústria. Disponível em: http:// www.firjan.com.br/firjan/default.htm. Acesso em: 03/08/2020.

FIRJAN. Visões de Futuro: Potencialidades e Desafios para o Estado do Rio de Janeiro nos próximos 15 anos. Setembro de 2014. Disponível em: http://publicacoes.firjan.org.br/visoesdefuturo2014/ files/assets/basic-html/page1.html. Acesso em: 03/08/2020.

FORTES, A.; OLIVEIRA, L.D.; SOUSA, G.M. A COVID-19 na Baixada Fluminense: Colapso e apreensão a partir da periferia metropolitana do Rio de Janeiro, Espaço e Economia [Online], 18 | 2020, 21 de abril de 2020. Disponível em http://journals.openedition.org/espacoeconomia/13591 Acesso: 03/08/2020.

GOVERNO DO ESTADO. Lei $n^{0}$ 5.636, Dispõe sobre política de recuperação industrial regionalizada e dá outras providências, de 06 de janeiro de 2010.

GOVERNO DO ESTADO. Projeto de Lei Complementar nº 10/2015, que “dispõe sobre a Região Metropolitana do Rio de Janeiro, sua composição, organização e gestão, define as funções públicas e serviços de interesse comum, cria a Agência Executiva da Região Metropolitana do Rio de Janeiro e dá outras providências".

GOVERNO DO ESTADO. Plano Estratégico de Desenvolvimento Urbano Integrado da Região Metropolitana do Rio de Janeiro. Rio de Janeiro: Consórcio Modelar a Metrópole/Quanta-Lerner, 2018. Disponível em: https://www.modelarametropole.com.br/documentos/\#documentos-produtos

HARVEY, D. O Novo Imperialismo. 2.ed. São Paulo: Ed. Loyola, 2005.

IBGE. XII Censo Demográfico - Censo 2010, 2010. Disponível em: https://censo2010.ibge.gov.br/ IBGE. IBGE Cidades, 2020 Disponível em: https://cidades.ibge.gov.br/ 
LAGO, L.C. A "periferia" metropolitana como lugar do trabalho: da cidade-dormitório à cidade plena. In: Cadernos IPPUR, Rio de Janeiro, Ano XXI, №2, 2007, p.9-28.

KLINK, Jerome. Development Regimes, Scales and State Spatial Restructuring: Change and Continuity in the Production of Urban Space in Metropolitan Rio de Janeiro, Brazil. International Journal of Urban and Regional Research, Volume 37.4 July 2013 1168-87

LIMONAD, E. Os Lugares da Urbanização: o caso do interior fluminense. Tese de Doutorado. São Paulo: FAU-USP, 1996.

LOPES, G.O. Novos espaços: os condomínios logísticos e a expansão capitalista no município de Seropédica (RJ). Dissertação (mestrado). Rio de Janeiro: PUC-Rio, 2018.

NORTH, D. Teoria da localização e crescimento econômico regional. In: SCHWARTZMANN, J. (org.). Economia regional: textos escolhidos. Belo Horizonte: CEDEPLAR/UFMG, 1977, p. 333-343.

OLIVEIRA, L.D. A emersão da região logístico-industrial do Extremo Oeste Metropolitano fluminense: reflexões sobre o processo contemporâneo de reestruturação territorial-produtiva. Espaço e Economia [Online], 7, 2015. Disponível em https://journals.openedition.org/ espacoeconomia/1781. Acesso: 03/08/2020.

OLIVEIRA, P.M. Empreendedorismo Urbano Periférico: um estudo sobre os municípios da Borda Oeste Metropolitana do Rio de Janeiro. Dissertação. (Mestrado em Desenvolvimento Territorial em Políticas Públicas). Seropédica: Universidade Federal Rural do Rio de Janeiro, 2017.

PPGDT. Levantamento de temáticas em Dissertações do Programa de Pós-Graduação em Desenvolvimento Territorial e Políticas Públicas. Disponível em: http://cursos.ufrrj.br/posgraduacao/ppgdt/ dissertacoes/page/2/. Acesso: 11/08/2020.

RODRIGUES, A.O. Baixada Fluminense: inovações e permanências. Tese (Doutorado) - IPPUR/ Universidade Federal do Rio de Janeiro, 2014.

SCHVARSBERG, B. A carroça ao lado do avião: o direito à cidade metropolitana em Brasília. Cadernos Metrópole, v. 19, p. 313-334, 2017.

SILVA, R.D. Indústria e Desenvolvimento Regional no Rio de Janeiro. Editora da Fundação Getúlio Vargas e Fundação de Amparo à Pesquisa do Estado do Rio de Janeiro, Rio de Janeiro, RJ, 2012.

SILVA, R.D. Rio de Janeiro: Crescimento, transformação e sua importância para a economia nacional (1930-2000). Dissertação de Mestrado. Campinas: IE-Unicamp, 2004.

SILVA, R.D. Royalties e desenvolvimento regional: uma reflexão sobre os desafios do Rio de janeiro. IN: Monteiro Neto, A., Castro, C. \& Brandão, C. (org.) Desenvolvimento Regional no Brasil política, estratégias e perspectivas. IPEA, Brasília, DF, 2017.

SILVA, R.D. AZEVEDO, N.F. El Arco Metropolitano como expresión del desarrollo desigual en la Región Logístico-Industrial del Extremo Oeste Metropolitano Fluminense. Proyección (Mendoza. en Línea) , v. XII, p. 26-55, 2018.

SILVA, R.D. ; IRAZABAL-ZURITA, C. . Boom, Burst, and Doom: The Petrochemical Complex of Rio de Janeiro as Catalyzer of Urban-Regional Development. REVISTA BRASILEIRA DE ESTUDOS URBANOS E REGIONAIS (ANPUR) , v. 21, p. 351-370, 2019.

SILVA, R.D. OLIVEIRA, P.M. Baixada Fluminense: Notas sobre os impactos iniciais do Arco Metropolitano. In: Revista Continentes (UFRRJ), ano 6, n. 11, 2017.

SOBRAL, B. L. Metrópole do Rio e projeto nacional. Uma estratégia de desenvolvimento a partir de complexos e centralidades no território. Rio de Janeiro: Garamond, 2013 
SOUZA, T.R. O papel da Ideologia na expansão urbana: a questão econômica e os impactos socioambientais do Arco Metropolitano do Rio de Janeiro. Dissertação de Mestrado - FAUUSP. São Paulo, 2015. 212p.

\section{NOTAS}

1. Cabe destacar o papel do Programa de Pós-graduação Desenvolvimento Territorial e Políticas Públicas da Universidade Federal Rural do Rio de Janeiro, criado em 2014, que conta com 16 dissertações defendidas e outras tantas em desenvolvimento cujos objetos de estudos são municípios do oeste metropolitano.

2. Ver Lei Complementar № 184 de 27 de dezembro de 2018, que dispõe sobre a composição da Região metropolitana do Rio de Janeiro, composta pelos Municípios do Rio de Janeiro, Belford Roxo, Cachoeira de Macacu, Rio Bonito, Duque de Caxias, Guapimirim, Itaboraí, Itaguaí, Japeri, Magé, Nilópolis, Niterói, Nova Iguaçu, Maricá, Paracambi, Petrópolis, Queimados, São Gonçalo, São João de Meriti, Seropédica, Mesquita,e Tanguá.

3. Três municípios estão entre os menos populosos (Paracambi, Seropédica e Japeri) IBGE, 2010

4. Dos cinco municípios que compõem esse recorte, três deles apresentam as menores densidades demográficas da região (Itaguaí, Paracambi e Seropédica) IBGE, 2010.

5. Essa sub-região aparece para a FIRJAN como a que apresenta grande quantidade de terrenos vazios que estariam disponíveis para investimentos.

6. Inclusão Do Distrito Industrial De Barra Do Piraí, Distrito Industrial De Pinheiral E Distrito Industrial Da Posse (Petrópolis). LEI № 5792, DE 22 DE JULHO DE 2010.

7. Que já constavam na primeira redação (janeiro de 2010). Cabe ressaltar que os incentivos estão limitados às áreas dos distritos não favorecendo o restante das áreas municipais.

\section{RESUMOS}

O presente artigo objetiva apresentar as bases do dinamismo econômico da região designada Oeste Metropolitano do Rio de Janeiro através da análise da trajetória de crescimento e investimento de dois municípios: Seropédica e Japeri. o estudo mostra como esses territórios foram atingidos pela dinâmica social-desenvolvimentista do período pós-2003, trazendo dados acerca do investimento. A análise demonstra que a proximidade com os principais eixos de transportes e a grande oferta de terras foram determinantes para se efetivar o chamado perfil logístico-industrial.

This article aims to present the basis of the economic dynamism of the region called the Metropolitan West of Rio de Janeiro through the analysis of the growth and investment trajectory of two municipalities: Seropédica and Japeri. The study shows how these territories 
were affected by the social-developmentalist dynamics of the post-2003 period, bringing data about the investment. The analysis demonstrates that the proximity to the major transport axes and the large offer of land were decisive for the so-called logistic-industrial profile to be effective.

Este artículo tiene como objetivo presentar las bases del dinamismo económico de la región denominada Borde Occidental Metropolitano del Estado de Río de Janeiro a través del análisis de la trayectoria de crecimiento e inversión de dos municipios: Seropédica y Japeri. El estudio muestra cómo estos territorios fueron afectados por la dinámica socio-desarrollista del período post-2003, aportando datos sobre la inversión. El estudio muestra que la proximidad a los grandes ejes de transporte y la gran oferta de suelo fueron determinantes para que el llamado perfil logístico-industrial fuera efectivo.

Cet article vise à présenter les fondements du dynamisme économique de la région dite de la périphérie ouest métropolitaine de l'État de Rio de Janeiro à travers l'analyse de la trajectoire de croissance et d'investissement de deux communes: Seropédica et Japeri. L'étude montre comment ces territoires ont été affectés par la dynamique socio-développementaliste de la période post-2003, apportant des données sur l'investissement. L'étude montre que la proximité des grands axes de transport et la large offre de terrains ont été déterminantes pour que le profil dit logistique-industriel soit efficace.

\section{ÍNDICE}

Mots-clés: Rio de Janeiro - industrie - investissement - métropolisation - périphérie.

Keywords: Rio de Janeiro; industry; investment; metropolization; periphery.

Palabras claves: Rio de Janeiro - industria - inversión - metropolización - periferia.

Palavras-chave: Rio de Janeiro; indústria; investimento; metropolização; periferia.

\section{AUTORES}

\section{ROBSON DIAS DA SILVA}

Professor do PPGDT e PPGCTIA da Universidade Federal Rural do Rio de Janeiro. Doutor em Economia pela Universidade Estadual de Campinas. Jovem Cientista do Nosso Estado (Faperj) para o biênio 2018-2020. E-mail: robsondsilva@gmail.com.

\section{PATRÍCIA MATIAS DE OLIVEIRA}

Doutoranda em Geografia na Universidade Federal do Rio de Janeiro. Mestre em Desenvolvimento Territorial e Políticas Públicas pela Universidade Federal Rural do Rio de Janeiro. E-mail: patricia_matias@hotmail.com.br.

\section{NATHÁLIA FIGUEIREDO DE AZEVEDO}

Doutoranda em Planejamento Urbano e Regional na Universidade Federal do Rio de Janeiro. Mestre em Desenvolvimento Territorial e Políticas Públicas pela Universidade Federal Rural do Rio de Janeiro. E-mail: azevedo.nfa@gmail.com. 